\section{Hyponatraemic convulsion associated with desmopressin and imipramine treatment}

Drs M Hamed, H Mrtchell, and D J Clow (Dumfries and Galloway Royal Infirmary, Dumfries DG1 4AP) write: In September 1992 a 10 year old boy was admitted unconscious (Glasgow coma scale 6) and hypothermic (temperature $33^{\circ} \mathrm{C}$ ). $\mathrm{He}$ had previously had primary nocturnal enuresis, for which he was initially given intranasal desmopres$\sin 20 \mu \mathrm{g}$ at night for two months; later the dose was increased to $40 \mu \mathrm{g}$ for five months, after which imipramine $25 \mathrm{mg}$ at night was added. Two weeks before admission he had had a minor head injury. On the day of admission he had fine twitching movements of both hands and clenched teeth, which progressed to a generalised tonic seizure lasting 10 minutes and which was terminated by $5 \mathrm{mg}$ of rectal diazepam. The cause of his deep coma was not clear.

His weight was $31.8 \mathrm{~kg}$ and his height $138.8 \mathrm{~cm}$, both measurements being above the 50 th centile. His haemoglobin level was $125 \mathrm{~g} / \mathrm{l}$, white blood cell count $19 \times 10^{\circ} /$, neutrophils $16 \cdot 2 \times 10^{\circ} / 1$. Although blood urea, calcium, ammonia, and glucose concentrations were normal, his serum sodium was $113 \mathrm{mmol} /$, serum potassium $3.3 \mathrm{mmol} / \mathrm{l}$, plasma osmolality $244.7 \mathrm{mmol} / \mathrm{l}$, and urine osmolality $561 \mathrm{mmol} / \mathrm{l}$. Hyponatraemic convulsion was diagnosed and treated.

There was progressive clinical and biochemical improvement over 36 hours, confirming the diagnosis of hyponatraemic convulsion secondary to desmopressin or imipramine, or both. He was discharged after four days without medication and reviewed in the outpatient clinic, where he appeared in good health.

A drug overdose was unlikely because of parental supervision. The other possibility was hyponatraemia induced by imipramine ${ }^{12}$ or desmopressin. ${ }^{34}$ Although the manufacturer of desmopressin recommends reassessment after three months' treatment,' this is often ignored. We would recommend that imipramine is not prescribed in combination with desmopressin, that parents should be warned of the dangers of excessive fluid intake when desmopressin is used, and that the initial trial period before reassessment should be only four weeks.

1 Mitch RA, Lee AK. Syndrome of inappropriate ADH secretion with imipramine. Drug IntelMoses AM, Miller M. Drug induced dilutional Moses AM, Miller M. Drug induced dilutional 1234-9.

3 Blanchard P, Brossien JP. Convulsions due to severe hyponatraemia following desmopresin as treatment of enuresis. Archives Fran caises de Pediatric 1991;48:589.

4 Bamford MFM, Cruickshank KG. Danger of intranasal desmopressin for nocturnal
345 .

ABPI Data Sheet Compendium. London: ABPI 1991-2:472.

\section{Hemiplegia after measles, mumps, and rubella vaccination}

Drs A H SACKey and R L BroADHEAD (Royal Liverpool Children's Hospital, Liverpool L12 2AP) write: A previously healthy 16 month old irl was admitted with an acute prolonged right sided tonic clonic convulsion associated with a fever of $39 \cdot 4^{\circ} \mathrm{C}$, having received measles, mumps, and rubella vaccine (Immravax) six days earlier. She was subsequently found to have a flaccid lef hemiparesis, together with complex partial seizures, which were subsequently controlled with sodium valproate. Consciousness returned to normal within two weeks, bu she was then noted to have a left homonymous hemianopia, which persisted for three months. On review after six months there was some mild weakness of the right leg, but the hand appeared normal.

On admission blood glucose and electrolyte concentrations were normal, and bacterial, viral, and serological studies showed no evidence of infection. Serial cranial computed tomography showed initial mild generalised oedema and a persistent subarachnoid cyst. An electroencephalogram one week after admission was grossly abnormal with diffuse slow activity consisten with encephalopathy. Six month ater it looked normal.

Systemic symptoms attributable to measles, mumps, and rubella vaccination usually occur 5-12 days after immunisation.' There have been reports of severe neurological reactions after immunisation with such vaccines given singly or in combination (Committee on Safety of Medicines, personal communication).$^{24}$ Febrile convulsions are well recognised after vaccination agains measles, mumps, and rubella, ${ }^{5}$ but we are not aware of a previous report of prolonged hemiparesis.

This reaction was probably nonspecific in that the high fever induced by the vaccine, in association with the added risk factors of susceptible age and maternal history of epilepsy, precipitated the prolonged convulsion and resulting encephalopathy.

1 Reynolds JES, Parsitt K, eds. The extra pharmacopoeia (Martindale). 29th

2 Tavanger J, Wiholm BE. Low incidence of side effects reported after measles, mumps and rubella vaccine. Lakartidringer 1987;84: rubella

Griffin MR, Ray WA, Mortimer EA, Feniche GM, Schaffner W. Risk of seizures after MMR immunization. Paediatrics $1991 ; 88$ : 881-5.

4 Udate on MMR vaccination. Drug Ther Bull 1991;29:61-2.
5 Isaacs D, Menser M. Modern vaccines. Measles, mumps, rubella, and varicella. Lancet 1990;335:1384-7.

6 Norman RM. Neuropathological findings in acute hemiplegia in childhood. In: Bax M Mitchell R, eds. Acute hemiplegia in childhood. London: Spastics SocietyHeinemann, 1962.

Psychomotor retardation and semistuporous state with \section{paroxetine}

Drs J Lewis, J Braganza, and $T$ Williams (St Tydfil's Hospital, Merthyr Tydfil) write: Specific serotonin reuptake inhibitors have an advantage over tricyclic antidepressants in producing less sedation and psychomotor retardation.' We present a patient who developed severe psychomotor retardation, becoming semistuporous, when taking the serotonin reuptake inhibitor paroxetine.

A 67 year old mildly mentally handicapped woman was admitted with an agitated depressive illness. Her depression had endogenous features with occasional delusional beliefs. She was started on paroxetine $20 \mathrm{mg}$ daily, increased to $40 \mathrm{mg}$ with thioridazine $10 \mathrm{mg}$ thrice daily. Trifluoperazine $10 \mathrm{mg}$ was added after a few days because she remained deluded. After three weeks her agitation subsided, and she appeared sedated; consequently the thioridazine and trifluoperazine were stopped. She deteriorated, however, becoming progressively more withdrawn, immobile, and unreactive, and rarely speaking. Her muscle tone remained normal, with no abnormal movements, but she could not feed or care for herself, and was occasionally incontinent. Physical examination and investigations, including computed tomography and electroencephalography, failed to show any cause for her deterioration. It was not until paroxetine was stopped (two weeks after withdrawal of the neuroleptics) that she began to improve, and after five days had completely recovered.

Two months later her depression recurred, and she restarted paroxetine $20 \mathrm{mg}$ daily, with $3 \mathrm{mg}$ of haloperidol. After two weeks she again developed psychomotor retardation, lapsing into a semistuporous state. As before, this did not resolve until paroxetine (but not the haloperidol) was withdrawn.

The patient did not have any renal or hepatic impairment that might have increased her sensitivity to paroxetine. However, it is unclear whether paroxetine was solely responsible for the adverse reaction, or whether the neuroleptics also played a part. Furthermore, mentally handicapped people are known to react in idiosyncratic or paradoxical ways to medication. The Committee on Safety of Medicines has reports of four further cases of stupor asso-

ciated with paroxetine treatment. None of the patients was reported as concurrently receiving neuroleptics, nor were they elderly.

1 Boyer WF, Blumhardt CL. The safety profile of paroxetine. I Clin Psychiatry 1992:53 (suppl):61-6.

\title{
Muscle cramps related to
} corticosteroids

Drs $J$ Lear and $R$ G Daniels (Northampton General Hospital NN1 5BD) write: Muscle cramps have been reported with $\beta_{2}$ agonists and muscle pain with beclomethasone dipropionate reported to the Committee on Safety of Medicines, but there have been no reports of muscle cramps with prednisolone.

A 48 year old non-smoking woman with mild asthma had been started four years earlier on a twice daily regimen of fenoterol hydrobromide $90 \mu \mathrm{g}$ and ipratropium bromide $36 \mu \mathrm{g}$ per metered inhalation. During that time each administration of prednisolone $(40 \mathrm{mg}$ orally once daily) or beclomethasone dipropionate $(200 \mu \mathrm{g}$ twice daily by inhaler) precipitated severe muscle cramps. Starting one day after the dose, they mainly affected her left calf. They occurred mostly at night with three or four episodes lasting five minutes and subsiding sponaneously. Direct pressure and stretching did not help. They stopped within three days of her finishing the corticosteroids, and did not reoccur. While taking the corticosteroids she did not alter her use of inhaled $\beta_{2}$ agonists. Serum potassium concentration at this time was normal.

In the summer her hay fever was occasionally severe enough to warrant topical beclomethasone dipropionate (200 $\mu \mathrm{g}$ twice daily each nostril) for one week and oral corticosteroids (prednisolone $20 \mathrm{mg}$ once daily) for three days. The muscle cramps were again precipitated, although she was not using inhaled $\beta_{2}$ agonists at the time as her asthma was not a problem. She did not complain of weakness in her legs, and there was no muscle wasting or diminished power.

She had had severe pneumonia secondary to measles at the age of 6 , and was diagnosed as asthmatic at the age of 21 . She had left sided varicose 